\title{
Risk Analysis of Enterprise Financial Derivatives: Evidence from MGRM Company
}

\author{
Yulin Liu ${ }^{1, \dagger}$ Jiayi $\mathrm{Lu}^{2, \dagger}$ Shihang $\mathrm{Wu}^{3, \dagger}$ Jiaqi $\mathrm{Xu}^{4, *}, \dagger$ \\ ${ }^{1}$ Academy of Social Sciences, University of Manchester, M13 9PL, Manchester, United Kingdom \\ ${ }^{2}$ Department of management, University of Toronto, M1C 1A4, Toronto, Canada \\ ${ }^{3}$ School of Economics and Statistics, Guangzhou University, 510006, Guangzhou, China \\ ${ }^{4}$ School of Business, INTI International University, 71800 nilai, Negeri Sembilan, Malaysia \\ *Corresponding author.Email: i18014317@student.newinti.edu.my \\ These authors contributed equally.
}

\begin{abstract}
The hedging of financial derivatives is crucial for enterprise risk management. However, enterprises often ignore the complexity and leverage of derivatives transactions as well as add speculation in hedging operations, which attributes to the failure of hedging. A bad hedge will bring huge losses to enterprises and even lead to the risk of bankruptcy. Therefore, learning from the failure of others is helpful to improve the risk awareness of enterprises. Taking the bankruptcy of Metallgesellschaft Refining and Marketing (MGRM) company as an example, this paper investigates the conditions for the usage of financial derivatives based on SWOT and PEST as well as analyses the hedging failure process and related risks. According to the results, financial derivatives need to recognize the nature of transactions, prevent and control technical operational risks and actively manage after position establishment. These results shed light for risk analysis of financial derivatives.
\end{abstract}

Keywords: Financial derivatives, Metallgesellschaft Refining and Marketing, SWOT analysis, PEST analysis

\section{INTRODUCTION}

Derivative products, also known as financial derivatives, are derived from underlying financial asset, whose original meaning in English means something based on another source. They were important parts of global financial innovation in the 1980s. Nowadays, the basis for derivative exchanges includes interest rates, exchange rates, commodities, stocks and other indexes. The term "derivatives" is also used to include the abovementioned derivatives, or debt instruments that include options, and dismantling other instruments, e.g., debt instruments created by principal and interest income".

For companies, derivatives are undoubtedly the best choice to lock in commodity prices and offset market risks. Enterprises complete hedging transactions through a series of positions and operations aimed at forward positions. However, due to the complexity and leverage of financial derivatives, their hedging operations have certain risks, i.e., companies often suffer potential losses due to hedging operations, and may even face the risk of bankruptcy. Therefore, the risk analysis of financial derivatives is becoming more and more important. Analysing the various types of risks and finding the reasons and results of the company's hedging failure will help other companies search better ways of risk management. In order to obtain conclusions and enlightenment, this article will take the derivative operations of Metallgesellschaft Refining and Marketing (MGRM) as an example to explore how a powerful company made itself bankrupt through a failed hedging operation.

On the one hand, theoretical analysis shows that derivatives can increase tax-saving benefits, reduce the probability of bankruptcy, alleviate under-investment, and improve entrusted agency, thereby reducing the enterprise's risk-taking. In empirical researches, some support the use of derivatives to enhance the company's value, while some scholars believe that it cannot. Allayannis and Weston [1] used Tobin`s Q to represent the value of a company. Based on a sample of US nonfinancial companies, they found that the premium was $3 \%$ to $8 \%$, supporting the value theory. Guay and Kothari [2] used more than 200 large non-financial 
companies in the United States, and found that hedging has little effect on company value. They believe that exchange rate and interest rate risks are secondary risks, and the value impact is not significant. Kim et al. [3] examined the effect of incentives for risk management based on managers' compensation on the use of derivative. According to the results, incentives endogenous to managers' compensation can cause managers to increase or reduce corporate risk in order to maximize their expected returns. It can be seen that the conclusions of scholars on the relationship between the use of derivatives by enterprises and the value and risk of enterprises are not very consistent. Obviously, this is related to factors such as the number of samples selected, the industry to which the enterprise belongs, and the size of the enterprise. Nevertheless, it is generally believed that the rational use of derivatives is conducive to enhancing corporate value and reducing corporate risks to a certain extent.

On the other hand, some scholars have also pointed out that derivatives may cause companies to take additional risks. Black and Scholes [4] and Merton [5] stated that for a company with liabilities, its shareholders can be regarded as long parties in a European call option contract with corporate value as the underlying asset. Besides, the creditors are correspondingly on the short side, based on the option pricing theory, the higher the volatility of corporate value, the more beneficial to shareholders and not to creditors. Later, based on this theory, Jensen and Meckling [6] and Myers [7] proposed that in order to transfer wealth from creditors to shareholders, companies operating in debt have the urge to increase risks, which implies that financial derivatives can help to realize the purpose of wealth transfer for enterprises. Tobin [8] believes that the financial derivatives market will encourage speculative trading, which will increase unnecessary risks in the operation of the economy. Copeland and Joshi [9] and Hagelin and Prambourg [10] also stated that once a company chooses the wrong derivative or has an improper motivation to engage in derivative transactions, it will weaken the effectiveness of risk hedging and put the interests of the company and shareholders in excess risk.

This article uses SWOT analysis and PEST analysis to investigate the competitive advantages of MGRM in this industry. It also estimates the company's case in chronological order, explains the impact of basis on the returns of derivatives, and evaluates its derivatives risks in a qualitative way. Afterward, the origination for the derivatives risks of MGRM is demonstrated: market price risks, derivative basis risks and operational risks of company managers. This can give us some enlightenment on corporate governance, i.e., management should establish a good sense of risk, realize the complexity of financial products as well as hedging cannot be made for profit.

First of all, we will take MGRM as an example to analyse the industry and business in which it is located in order to obtain a good company's operating conditions and motivations for using derivatives. Then, we will explain the company's entire process from hedging business to final bankruptcy, analyse the risk types of derivatives, and finally draw our conclusions.

\section{FIRM DESCRIPTION}

\subsection{Introduction of MGRM}

Metallgesellscgaft is an old industrial company with a history of more than 100 years. Its business scope includes metal smelting, mining, machinery manufacturing, engineering design and contracting extra, ranking about 13th and fourth among German industrial groups. Metallgesellschaft Refining and Marketing (MGRM for short) is the American subsidiary of the German company Metallgesellschaft. MGRM's main business is trading oil products. This company was known for their steadily and had long been the investments of choice for financial institutions and family-owned banks.

\subsection{SWOT analysis}

SWOT analysis is an analysis that based on internal and eternal competitive environments and conditions, which may be closely related to the research objects. This will be arranged in accordance with the matrix form through investigation. When all kinds of factors are matched and analyzed, a series of corresponding conclusions are drawn and the conclusions usually have a certain decision. Based on this method, the situation of the research objects could be comprehensively, systematically and accurately studied, in order to formulate corresponding development strategies, plans and countermeasures according the analysis. Thereinto, $\mathrm{S}$ refers to strength, $\mathrm{W}$ refers to weakness, $\mathrm{O}$ refers to opportunities, $\mathrm{T}$ refers to threats. According to the complete concept of enterprise competitive strategy, a strategy should be an organic combination of what an organization could do from strengths and weakness, and what it could do refers to opportunities and threats. For MGRM, it's SWOT matrix is given in Table 1. 
Table 1.SWOT Analysis of MGRM

\begin{tabular}{lllll}
\hline $\begin{array}{l}\text { SWOT } \\
\text { Analysis }\end{array}$ & S(Strengths) & $\mathrm{W}$ ( Weaknesses ) & $\mathrm{O}$ ( Opportunities ) & $\mathrm{T}$ ( Threats ) \\
\hline$(1)$ & $\begin{array}{l}\text { Good business and } \\
\text { operation }\end{array}$ & Stack-and-roll strategy & $\begin{array}{l}\text { The market is in } \\
\text { backwardation }\end{array}$ & Basis risk
\end{tabular}

$(2)$

$$
\begin{aligned}
& \text { Large number of } \\
& \text { positions } \\
& \text { One of the Industry } \\
& \text { leader }
\end{aligned}
$$$$
\text { Lot of trading cost }
$$$$
\text { Margin and mark-to- }
$$$$
\text { market system }
$$

Uncertainty of borrowing money
Seen in Table 1, as the leading company in oil industry, MGRM has good business and operations, large number of jobs positions, which are the strengths of the company. These advantages are conducive to MGRM having good development resources, so as to expand its development advantages. Whereas, there are some weakness of MGRM, which may obstruct MGRM' $\mathrm{s}$ development. To begin with is the stack-and-roll strategy. The decline in crude oil prices has led to a decline in the value of long crude oil futures. The risk of forced liquidation of derivatives trades because of the leverage effect of derivatives and special nature of "margin calls". In this situation, the rolling trading pattern may increase the likelihood of risk. Moreover, the large amount of trading cost and the weak awareness of risk in management may increase the risk of trading to some extent. There are also some threats for MGRM. Normally, it is the basic risk of trading in oil market, the margin and mark-to-market system and uncertainty of borrowing money. Nevertheless, MGRM has the opportunity to make profit as the backwardation situation in market, MGRM's potential hedging ability and the high volatility of oil prices. It may be found that although MGRM has a certain degree of resistance to risks and strong capital, its large number of positions, stack-and-roll trading model and management awareness of profit-seeking make the company threatened in the highly volatile oil price market.

\subsection{PEST analysis}

PEST analysis is the analysis of the macro environment, which refers to all the macro factors that affect industries and enterprises. In general, the analysis of macro environmental factors focuses on the four major external environmental factors that affect enterprises: P-politics, E-economy, S-society and Ttechnology. PEST analysis, as a comprehensive analysis method, could analyze the four types of environmental factors, explore the opportunities and threats that brought by the external macro environment to the enterprise and the proposed project. Additionally, it can provide the basis and reference for the analysis and decision-making of the development of the enterprise related fields and the formulation of the proposed project strategy. For MGRM, its PEST matrix are summarized in Table 2.

Table 2.PEST Analysis of MGRM

\begin{tabular}{lllll}
\hline $\begin{array}{l}\text { PEST } \\
\text { Analysis }\end{array}$ & P(Political) & E ( Economic ) & O ( Social ) & T ( Technological) \\
\hline$(1)$ & Free financial market & Developed financial & Social mentality of & Traditional industries are less \\
& & derivatives market & Speculating & profitable
\end{tabular}
The government has little
Active market transactions
Requirements for
No significant breakthrough
control over the economy
controlling risks
in new energy technology

Political environment includes a country's social system, the nature of the ruling party, the government's policies, etc. For MGRM Germany provides an environment of free financial market and little government regulation. Moreover, developed financial derivatives market and active market transactions offers 
an economics condition that suitable for oil trading. As for social conditions, values may affect people's recognition of behavior activities and people's attitude towards the content, way and results of organizing activities. Thus, social mentality of speculating and requirements for controlling risks could affect MGRM's investment and trading activities. In regard to technology, MGRM continues to invest and trade in the oil industry at its most basic level. Traditional industries are usually less profitable and MGRM did not achieve significant breakthrough in frontier of energy technology, which buried the curse for the future decline of MGRM.

\section{BANKRUPTCY CAUSED BY DERIVATIVES}

In the summer of 1993, IN order to develop longterm and profitable customer relationships, MG group's American subsidiary MGRM signed oil forward contracts with a number of customers. Under these contracts, MG will provide customers with about 160 million barrels of petroleum products at fixed prices over the next 10 years. The fixed price is set at the time of signing the forward contract and varies slightly from customer to customer. It is generally $\$ 3-5$ / BBL higher than the negotiated spot price (which is MG's markup). The mark-up for MG is the same regardless of the length of the contract. The contract also contains an option clause that allows the buyer to terminate the contract early if the NYMEX crude oil futures price for the previous month is higher than the MGRM contract price. MGRM will pay the buyer half of the difference between the two prices multiplied by the total number of outstanding contracts. The option is attractive to companies in financial distress or that no longer need oil. In some cases, MGRM also stipulated that the contract would automatically terminate if the current month's futures price exceeded a certain level. The price of oil on the contract is based on the current 12-month futures price plus a profit of 5-10\% per gallon (about \$2.1-4.20 per barrel). MG's fixed-price forward contracts expose it to rising energy prices. If energy prices rise in the future, MG company must supply oil to customers at an amount lower than the spot price, thus losing money. Otherwise, if prices rise high enough and remain high, $\mathrm{MG}$ will face significant losses. If oil prices fall in the future, MG will make a profit, but this is an economic activity, not a casino. In theory, MGRM should have bought an additional 10-year oil forward contract to hedge against volatile oil prices. However, there are no such long-term forward contracts in the market, i.e., MGRM addresses this problem by buying a lot of short-term oil futures and rolling them over to the next period after deducting the amount offered to customers at maturity. MG is using a short-term stackable hedging strategy using short-term oil futures contracts and OTC1 swaps. MG has taken long positions in futures and entered into OTC swaps with dealers, e.g., banks, which pay a fixed price and receive payments on floating energy prices. For a while, forward contracts brought in handsome profits, some as much as $\$ 5$ a barrel. Soon energy prices fell, futures rose and MGRM's cash was tight. Crude oil prices fell nearly $\$ 6$ a barrel between June and December 1993, forcing MGRM to spend \$900 million to maintain its hedging position. MG's new management, which cleared forward and short-term futures contracts, identified more than $\$ 1$ billion in losses.

\section{RISK CAUSE ANALYSIS}

After analyzing bankruptcy of MGRM, we conclude the main reasons for failure of this company. Overall, the main reason could fall into four categories. The complexity of derivatives trading, conflicting and misleading of accounting conventions, the risk of hedging is underestimated and lack of understanding at the supervisory board level. The decline in crude oil prices has led to a decline in the value of long crude oil futures. On account of the leverage effect of derivatives and the special nature of "margin calls", the risk of forced liquidation of derivatives trades. Moreover, the pattern rolling trading certainly increases the likelihood of risk, one for each trade, depending on market fluctuations. From the investors' points of view, there are three kinds of risks leading to the failure, with market risk, basis risk and operational risk, respectively.

The liquidity risk, including in market risk, it is the possibility of loss due to price changes. This kind of risk is a natural suspect for MGRM' s problems because futures hedging programs can require substantial infusions of cash to meet variation margin calls when prices are falling. In 1993, oil and oil product prices fell precipitously after OPEC failed to reach agreements on its production quotas, and substantial margin payments were due from MGRM to the NYMEX. In the accounting practice of Germany, it has traditionally adopted a conservative accounting and information disclosure system. This satisfied the principle of caution, but in this case, it was counterproductive, misleading investors and creditors who did not know the full extent of the matter and who did know some but did not have the time or ability to exercise professional judgment. To some extent, this blocked the company's financing channels, exacerbated the crisis, exaggerated the losses, and to some extent affected the decision-making of MG's board of supervisors.

MGRM did not have the ability and mechanism to deal with the risk of derivatives trading. Although the basis change was not anticipated, it was expected that crude oil prices would continue to fall in the short term. At this point, the company should consider that under the current accounting system, there may be a loss on its account that cannot be offset by the profits of the forward short position, which creates a liquidity 
shortage for the company. The company seems to have either failed to account for or underestimated the impact of this factor.

MGRM did not have the ability and mechanism to deal with the risk of derivatives trading. Although the basis change was not anticipated, it was expected that crude oil prices would continue to fall in the short term. In this case, the company should consider that under the current accounting system, there may be a loss on its account that cannot be offset by the profits of the forward short position, which creates a liquidity shortage for the company. The company seems to have either failed to account for or underestimated the impact of this factor, which is a kind of operational risk. Operational risk is associated with systems failures, natural disasters, or personnel problems. Nevertheless, operational risk also covers unapproved speculative activities by subordinates not detected by the senior management and board until serious losses have occurred. Referring to MGRM, for example, the General Accounting Office states that "poor operations controls were reportedly responsible for allowing losses at this firm to grow such levels."

In fairness to MGRM, however, ending a combined delivery program is costless. Unwinding bilateral contracts may require concessions from the party initiating the unwind. The supervisory board increased the cost of ending the program both by giving full concessions to its counterparties and by not following the common practice of unwinding both legs of a hedged transaction as close to simultaneously as possible.

If MGRM had not unwound its futures, the positive daily pays received when prices recovered in 1994 would have given it a substantial positive cash inflow. MGRM' s forced liquidation, moreover, sent a signal to MGRM' s OTC derivatives counterparties that its credit standing might be in jeopardy, thereby increasing calls for collateral to keep its OTC positions open and making it virtually impossible to establish new OTC positions.

\section{DISCUSSION}

When studying the frightening cases of huge losses caused by derivative transactions. The first thing one wants to find out is: Who is the culprit? Who is responsible for the loss?

The first is the judgment of the nature of the transaction. Financial derivative transactions contain high risks, which puts forward new management requirements for enterprises that produce and consume them. Financial derivative transaction itself is a doubleedged sword, which can be used not only for hedging, but also for speculation, trying to seek excess profit return from taking risks. Senior management must have sufficient professional knowledge or rely on professional traders to judge speculation.

The second is the technical risk of hedging. Hedging with financial derivatives often involves very complex mathematical models, in which the most important thing is to accurately determine the correlation between the real price and the selected derivative contract price. In the "MGRM" case, it is obvious that the model used to design hedging has not been strictly tested. Besides, there are disputes on key technical parameters such as term matching, hedging ratio and basis risk prevention. In addition, liquidity risk and credit risk will also seriously affect the formulation and implementation of hedging strategies.

Finally, it comes to the management after hedging. When it comes to hedging transactions with complex structures, e.g., the case of "MGRM", the post establishment management of positions is also very complex. The most important thing is that the senior management of the enterprise should let investors and creditors understand the hedging strategy adopted by the enterprise, as well as reach a consensus on dealing with the corresponding financing, profit and loss and other issues.

\section{CONCLUSION}

Contemporarily, more and more enterprises hedge risks through financial derivatives transactions. However, due to the complexity and high leverage of financial derivatives and the profit seeking behavior of management, enterprises often suffer huge losses in the hedging process, and even bankruptcy. Therefore, it is particularly important to learn from the failures of others. This paper analyses the negative case of MGRM company to understand the enterprise's environment and motivation to use derivatives based on SWOT and PEST analysis to investigate various risks through its failed hedging process and operation. Finally, some suggestions on risk management of financial derivatives are proposed.

According to the results, it is found that a successful derivative risk management needs the following three elements: strong risk management awareness, high-level technical analysis model and successful position management. The management needs to establish risk awareness and focus on hedging itself rather than speculative profits to offset transaction costs. Investors and traders should aware of the complexity and high risk of the product itself, strengthen knowledge training, establish a good income model and reduce the usage of operations that are not fully understood. The management shall control the size of the position, even in response to the change of margin, determine the scope of income and loss, and make the choice of whether to continue to maintain the position. 
Definitely, this paper has some limitations. Primarily, the event took place a long time ago. Both the financial environment and the oil industry environment are very different from now. The industry analysis only has the nature of reference. Secondly, MGRM is a bankrupt enterprise, and its parent company has also been acquired by others. Hence, it is difficult to get the current development status of the enterprise. Finally, we did not introduce successful cases in the industry and did not demonstrate the importance of derivative risk management from both positive and negative aspects. We are looking forward to adding more successful or failed cases of risk management to compare in the future to analyze. Overall, these results offer a guideline for risk analysis and paves a path for financial derivatives management.

\section{REFERENCES}

[1].Allayannis, G., and Weston, J.P., 2001. The Use of Foreign Currency Derivatives and Firm Market Value. Review of Financial Studies, (1): 243-276.

[2].Guay,Wayne,and Kothari,S.P.,2003. How Much Do Firms Hedge with Derivatives. Journal of Financial Economics, (3): 423-461.

[3].Kim, Young Sang, Nam, J., and Thornton, John H., 2008. The Effect of Managerial Bonus Plans on Corporate Derivatives Usage. Journal of Multinational Financial Management, (3): 229243.

[4].Black,F., and M.S.Scholes.,1973.The pricing of options and corporate liabilities. Journal of Political Economy 81,(3) : 637-654.

[5].Merton,R. C.,1974. On the pricing of corporate debt: The risk structure of interest rates. The Journal of Finance 29,(2) : 449-470.

[6].Jensen,M.C.,and W. H. Meckling.,1976.Theory of the firm: Managerial behavior, agency costs and capital structure. Journal of Financial Economics $3,(4): 305-360$.

[7].Myers,S.C.,1977.Determinants of corporate borrowing. Journal of Financial Economics 5,(2) : 147-175.

[8].Tobin.J., 1984. On the efficiency of the financial system. Lloyd's Bank Review 153,(2) : 1-15

[9].Copeland,T. E.,and Y.Joshi.,1996.Why derivatives do not reduce FX risk? Corporate Finance 13,(1) : 35-41.

[10].Hagelin,N.,and B.Pramborg.,2004.Hedging foreign exchange exposure:Risk reduction from transaction and translation. Journal of International Financial Management and Accounting 15,(1) : 1-20. 